\title{
DETERMINATION OF THE ANTIOXIDANT PARAMETERS OF COMMONLY AVAILABLE BLACK PINE (PINUS NIGRA J.F. ARNOLD)
}

\author{
Nuran Cikcikoglu Yildirim* , EsRef Gezer and Numan Yildirim ${ }^{1}$ \\ Department of Environmental Engineering, Munzur University, Tunceli, Turkey \\ Keywords: Black pine, Air pollution, Antioxidant enzymes, Biomonitor
}

\begin{abstract}
The antioxidant parameters of black pine (Pinus nigra J.F. Arnold) needles samples collected from different areas in the province of Diyarbakır, Turkey were studied. Black pine needles samples were collected from three different locations (Egil, Kosuyolu, and Diyarbakır industrial area) in the province of Diyarbakır in summer and winter seasons. The activity of enzymatic antioxidants such as superoxide dismutase (SOD), catalase (CAT), glutathione peroxidase $\left(\mathrm{GP}_{\mathrm{X}}\right)$, glutathione S-transferase (GST) and malondialdehyde (MDA) levels of the samples were determined by ELISA method. Results showed that SOD enzyme activities of the samples collected in summer from Kosuyolu and the industrial area decreased compared to the control group, but increased in the samples collected in winter from the same areas. When compared to the control group, it was observed that the MDA levels of the samples collected from Kosuyolu and the industrial area increased.
\end{abstract}

\section{Introduction}

Air pollution refers to the number of harmful substances in the atmosphere that are in higher concentration and have a longer residence time than the allowed range (Chou 2014). Urbanization and industrialization processes significantly contribute to the amount of various air pollutants such as $\mathrm{SO}_{2}, \mathrm{NO}_{2}, \mathrm{CO}, \mathrm{O}_{3}$ and particulate matter although several other gases such as $\mathrm{H}_{2} \mathrm{~S}, \mathrm{HF}, \mathrm{NH}_{3}$, $\mathrm{CH}_{4}$, etc. Kelly and Mudway (2003) and Schlesinger et al. (2006) studies in the literature reported increased oxidative stress due to air pollutant exposure and that antioxidants could offer certain level of protection. Air pollutants can enter into plant tissues via the stomata and increase the level of reactive oxygen species (ROS) (Nordberg and Arnér 2001, Radi et al. 2001). ROS cause various cellular injuries, including lipid peroxidation (LPO) (Foyer and Noctor 2005). ROS are removed by cellular defenses which include the superoxide dismutase enzyme (Mn-SOD, Cu/ZnSOD, and extracellular (EC)-SOD), catalase (CAT), glutathione peroxidase (Gpx), peroxiredoxins, and the nonenzymatic antioxidants, such as glutathione (Nordberg and Arnér 2001, Radi et al. 2001). SOD is believed to play a central role in the defense mechanism against oxidative stress. SOD is present in many aerobic organisms and in various parts of the cell such as chloroplast, mitochondria, and cytosol. SOD has been shown to be important in plant stress tolerance towards various environmental stresses. $\mathrm{GP}_{\mathrm{X}} \mathrm{s}$ are a family of a wide variety of isozymes that use GSH to reduce $\mathrm{H}_{2} \mathrm{O}_{2}$ and organic and lipid hydroperoxides, and thus protect plant cells against oxidative stresses (Noctor et al. 2002). CAT is a tetrameric enzyme containing heme which is found everywhere and catalyzes $\mathrm{H}_{2} \mathrm{O}_{2}$ into two molecules water and oxygen. Environmental stressors, depending on their intensity and duration, can result in increased or depleted CAT activity (Garg and Manchand 2009).

In the present study, the activities of antioxidant enzymes were investigated through $P$. nigra in Diyarbakır Turkey. The main reason for selecting $P$. nigra was its abundance in the study area. This study was aimed to determine the activity of antioxidant enzymes such as SOD, CAT, GP , GST and MDA levels in P. nigra in the different areas of Diyarbakir, Turkey.

*Author for correspondence: <nurancyildirim@gmail.com>. ${ }^{1}$ Tunceli Vocation School, Department of Herbal and Animal Production, Munzur University, Tunceli, Turkey. 


\section{Materials and Methods}

The plant samples (Pinus nigra) (n: 6 for each group) were collected from three different stations; namely Egil (S1: unpolluted), Kosuyolu (S2: city center) and an industrial area (S3) in summer and winter seasons and these stations are presented in Fig. 1. The tempature of the weather is $38.1{ }^{\circ} \mathrm{C}$ in August and $9.1{ }^{\circ} \mathrm{C}$ in winter. Egil was determined as the control group because it is used as a recreation area. Kosuyolu is an area in the city centre of Diyarbakir where the traffic is known to be very concentrated.

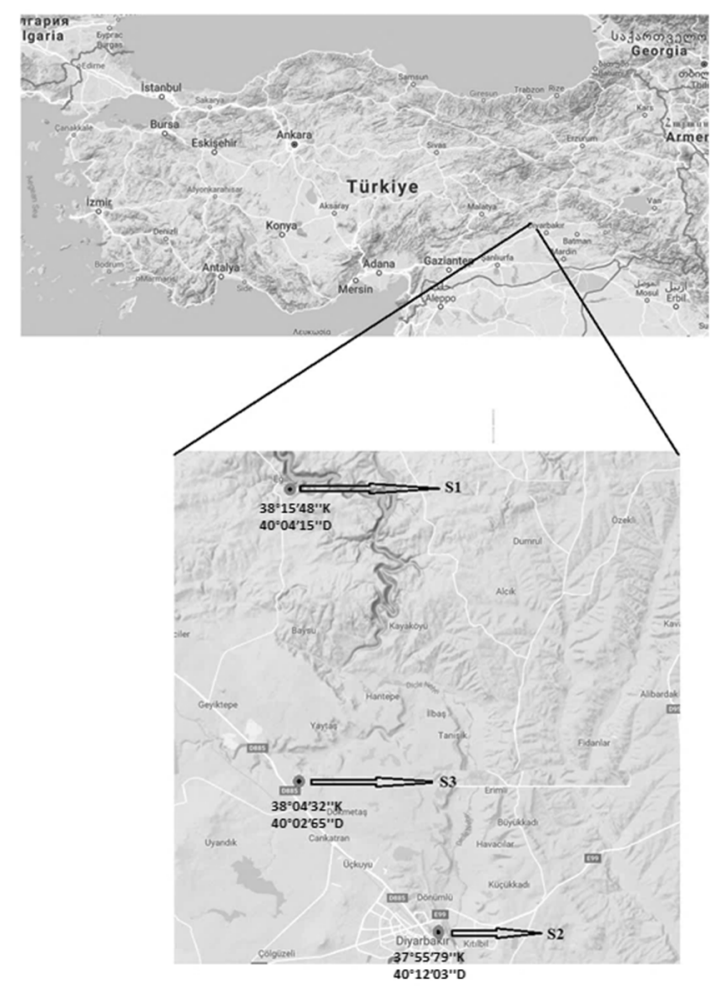

Fig. 1. Sampling stations, S1; Egil (reference area), S2; Kosuyolu (city center), S3; industrial area.

Six replicates of plant samples were prepared. Each expreriments were replicated three times. The needles of the collected plants were separated from their branches, cut into small pieces using scissors and then powdered. The $1 \mathrm{~g}$ fresh needles were homogenized with $10 \mathrm{ml}$ of a $50 \mathrm{mM}$ phosphate buffer $(\mathrm{pH}=7.6)$ containing $0.1 \mathrm{mM}$ Na-EDTA. The homogenized samples were centrifuged at $15.000 \mathrm{~g}$ and at $4^{\circ} \mathrm{C}$ for $15 \mathrm{~min}$.

The SOD, CAT, GPx, GST activities and MDA levels were determined to investigate the biochemical response in Pinus nigra. The biochemical biomarkers were analyzed according to the method used by Lauera et al. (2002) and Andra et al. (2011). The SOD, CAT, GP, GST and MDA commercial kits used in the study were purchased from Cayman Chemical Company. Catalog numbers: (CAT: 707002, SOD: 706002, GPx: 703102, GST: 703302, MDA: 10009055). The SOD assay kit utilizes a tetrazolium salt for the detection of superoxide radicals generated by xanthiane oxidase and hypoxhantine. One unit of SOD is defined as the amount of the enzyme needed to exhibit $50 \%$ dismutation of the superoxide radical. The CAT assay kit utilizes the 
peroxidatic function of CAT to determine of enzyme activity.This method is based on the reaction of the enzyme with methanol in the presence of an optimal concentration of $\mathrm{H}_{2} \mathrm{O}_{2} . \mathrm{GP}_{\mathrm{X}}$ assay kit measures GPx activity indirectly a coupled reaction with glutathione reductase. Oxidized glutathione produced upon reduction of hyroperoxide by $\mathrm{GP}_{\mathrm{X}}$, was recycled to its reduced state by glutathione reductase and NADPH. The oxidation of NADPH to NADP is accompanied by a decrease an absorbance at $340 \mathrm{~nm}$. The basis of the method is that the Cayman's Glutathione STransferase Assay Kit measures total GST activity by measuring the conjugation of 1-chloro-2,4dinitrobenzene (CDNB) with reduced glutathione. Conjugation caused an increase in $340 \mathrm{~nm}$ at Thermo multiscan microplate reader. This increase lead to a proportional increase in GST activity in the sample. In the MDA assays, the MDA-TBA adduct formed by the reaction of MDA and TBA under high tempature and acidic condition was measured colorometricallly at $540 \mathrm{~nm}$ at Thermo multiscan microplate reader.

The data were analyzed using PASW Statistics 18.0 (SPSS Inc., Chicago, IL, USA). One-way ANOVA and the Duncan's multiple range tests were used to evaluate the statistical differences among groups (S1, S2, S3).

\section{Results and Discussion}

When the SOD enzyme activities of the samples collected from Kosuyolu and the industrial area were compared with the control group, it was seen that the activity of the samples collected from Kosuyolu and industrial areas in summer decreased $(\mathrm{p}<0.05)$ while this activity increased in winter ( $<$ < 0.05) (Fig. 3A). The CAT enzyme activityof the samples collected from summer and winter seasons from Kosuyolu and the industrial area were compared with the control group and it was found that their activity decreased (p < 0.05) (Figs 2 and 3). When the $\mathrm{GP}_{\mathrm{X}}$ levels of the samples collected in summer from Kosuyolu and industrial area were compared to the control group, it was reported that no significant change occured in the activity of the Kosuyolu sample (p $>0.05)$ while the activity of the sample collected from the industrial area increased $(\mathrm{p}<0.05)$ No significant changes were reported for the samples collected in winter ( $p>0.05)$ (Figs 2 and 3). When GST enzyme activities of the samples collected from Kosuyolu and the industrial area in both summer and winter seasons increased compared to the control group. However, this increase was not statistically significant ( $p>0.05$ ) (Figs 2 and 3). When the MDA levels of the samples collected in summer from Kosuyolu and the industrial area were compared to the control group, it was found that this level decreased in the sample collected from Kosuyolu ( $p>0.05)$ while it increased in the sample collected from the industrial area $(\mathrm{p}<0.05)$. Significant inceases were also observed in the samples collected in winter $(\mathrm{p}<0.05)$.

Urban air pollution is a problem in developing and developed countries. As a result of the researches carried out on various cities in Turkey, it was seen that the air pollution rate is quite serious in the whole country. The province of Diyarbakır is also among the cities in which air pollution is high due to rapid migration and industrialization.

Bioindicators are organisms which are susceptible to pollutants, and it is possible to indirectly provide qualitative information about the pollution levels of a region by observing the biochemical changes of these organisms caused by atmospheric pollutants. Air pollutants can enter plant tissues through stomata, and cause an increase in ROS (Hipelli et al. 1996). ROS are increase in response to different abiotic stresses (Krishnamurthy and Rathinasabapathi 2013). Plant cells have several antioxidant defense mechanisms to protect against damage caused by ROS. The response of plants to various atmospheric pollutants varies according to the type of plant, the duration of exposure to the pollutants, the concentration of the pollutants and seasonal factors (Lee 2000). 

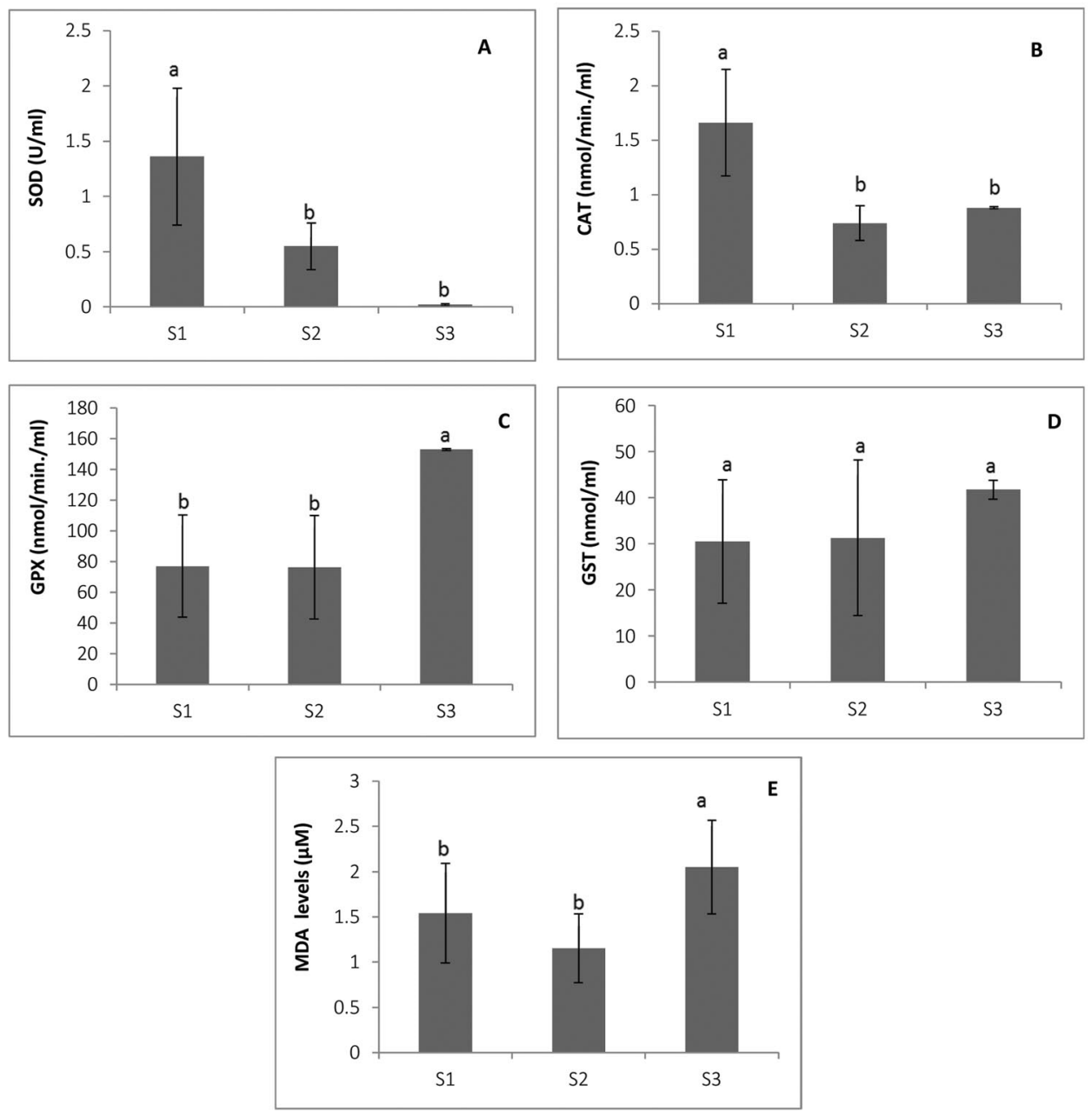

Fig. 2. A. SOD activity (U/ml), B. CAT activity (nmol/min/ml), C. GPx activity (nmol/min/ml) activities, D. GST activity ( $\mathrm{nmol} / \mathrm{ml}$ ), E. MDA levels (nmol/g tissue) of Pinus nigra collected from the different stations (S1, S2 and S3) in summer. The letters on the bar (a, b, c) show statistical differences of Duncan's multiple range test among the stations; ${ }^{\mathrm{abc}} \mathrm{p}<0.05$.

In this study; changes the antioxidant parameters of needles of Pinus nigra in the regions exposed to air pollution in the summer and winter were investigated. Pinus nigra was as it is evergreen. It is used as a biomonitor of airborne mercury pollution (Chiarantini et al. 2016). In a study conducted by Al-alam et al. (2017) on temporal air pollution variation in the Strasbourg region, Pinus nigra was used as a biomonitor. In another study conducted by Pukacka and Pukacki (2000) seasonal changes in antioxidant levels of Scots pine (Pinus sylvestris L.) needles exposed to industrial pollution were investigated. They indicated that the metabolism in the needles of different Scots pine populations, growing under pollutions, growing under pollution stress stress can be intensively directed on defense against ROS.

In various studies in the literature, increased SOD enzyme activity was found in the plants growing in soils with high $\mathrm{SO}_{2}$ and NOx emissions (Pukacka and Pukacki 2000). Patykowski and 
Kołodziejek (2016) investigated the changes in the antioxidant enzyme activities in European mistletoe response to the stress caused by the atmospheric pollutant $\mathrm{NO}_{2}$. They found a correlation between $\mathrm{NO}_{2}$ and enzyme activities. They reported a significant increase in SOD activity in the samples collected in autumn and an increase in CAT activity in the samples collected at the beginning of spring. Pukacka and Pukack (2000) investigated the seasonal changes
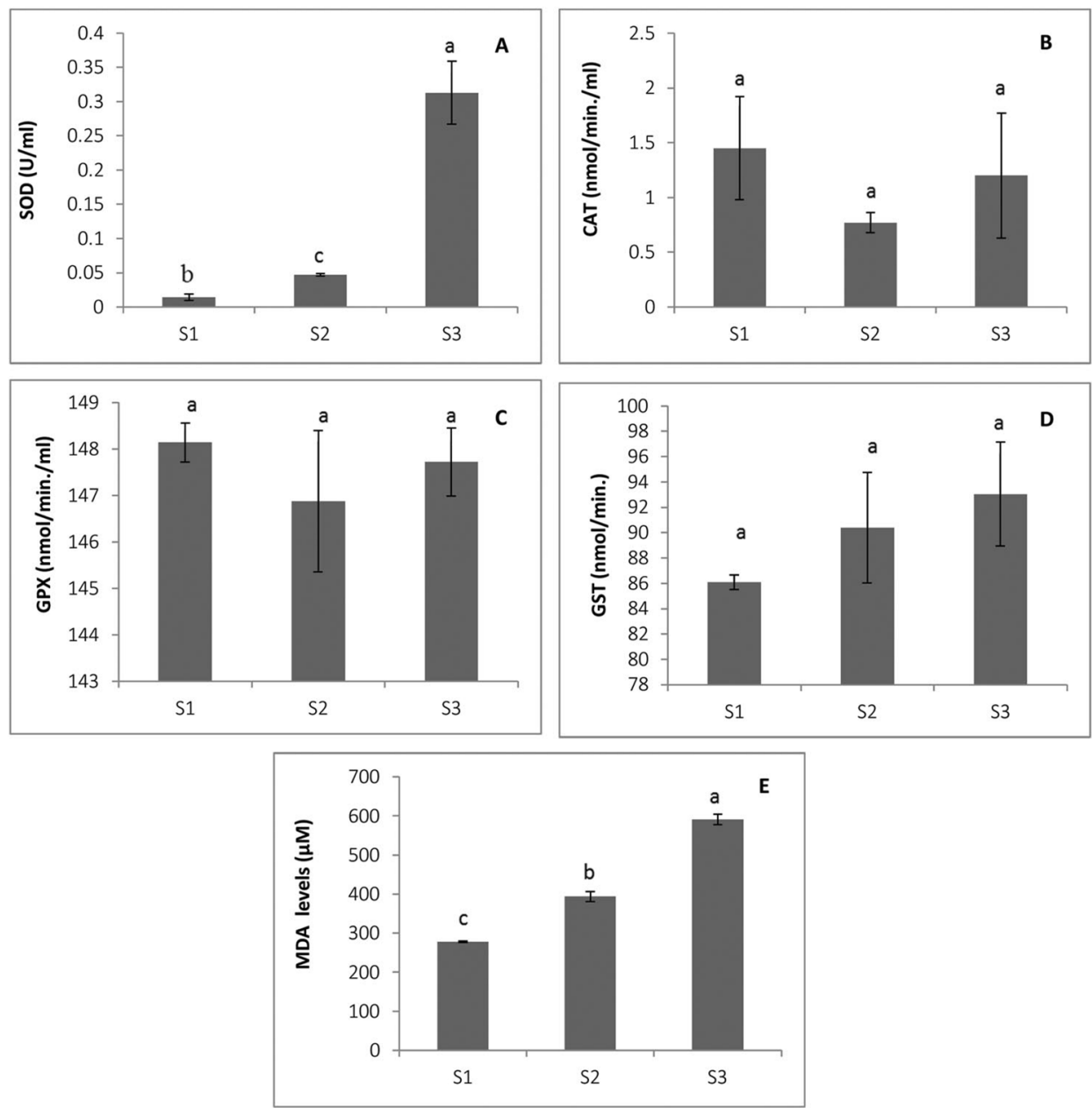

Fig. 3. A. SOD activity (U/ml) activities, B. CAT activity (nmol/min/ml), C. GPx activity (nmol/min/ml) activities, D. GST activity (nmol/ml), E. MDA levels (nmol/g tissue) of Pinus nigra collected from different stations (S1, S2 and S3) in winter. The letters on bar (a, b, c) show statistical differences of Duncan's multiple range test among the stations; ${ }^{\text {abc }} \mathrm{p}<0.05$.

in antioxidant enzyme levels in Pinus slyvestris exposed to industrial pollution and found that SOD enzyme activities were high in polluted areas. Other studies also showed that the SOD enzyme activity of plannts living in places where air pollution is intense increased in response to the pollution (Alanso et al. 2001, Schwanz and Polle 2001). In the present study, the SOD enzyme activity of the samples collected in summer from industrial area and Kosuyolu decreased 
compared with control, $(\mathrm{p}<0.05)$ while the activity of the samples collected in winter $(\mathrm{p}<0.05)$. In the present study, increased pollution and increased oxidative stress are thought to induce an increase in SOD enzyme activity. The different results between the samples collected during different seasons from the same areas the developmental phase difference and the variety of human-induced air pollution activities of that season.

Ghorbanli et al. (2007), investigated the changes caused by air pollution in the antioxidant enzyme activities of Nerium oleander and Robinia pseudoacacia. They reported higher CAT activity in the plants collected from the contaminated areas. In a study conducted by changes in the activity of antioxidant enzymes in two plant species exposed to air pollution in the city of Abidjan were determined and high CAT enzyme activity was found in both plants located in industrial areas and close to crowded roads. Kavitha and Shailaja (2016) evaluated the changes in the catalase enzyme to determine the air quality of polluted and less polluted areas and found that CAT activity was lower in polluted areas. Mutiu et al. (2009) investigated the changes in the antioxidant enzyme activities of wild plant species in polluted areas and found that CAT activity low in 9 out of 12 of the plants grown at 0-100 $\mathrm{m}$ of the sampling areas. Castillo (1987) reported that the activity of the catalase enzymes in various Ficus species located in polluted area showed low catalase activity. Smilarly, in the present study, CAT enzyme activity of the samples collected in summer and winter seasons from Kosuyolu and the industrial area decreased compared to the control.

Elloumi et al. (2017) assessed the GPx activities of the leaves and roots of trees at different distances from phosphate fertilizer plants. The GPx activities showed significant changes when compared to the uncontaminated areas. The results obtained showed that the GPx activities of the samples located of the contaminated areas had high oxidative stress indices when compared to the control group. In the present study, the $\mathrm{GP}_{\mathrm{X}}$ activity of the samples collected in summer from the industrial area increased $(\mathrm{p}<0.05)$ compared to the control group. Hasegawa-kurisu et al. (2008) investigated the GST activities of Epipremunum aureum exposed to cigarette smoke and found an increase. They suggested that GST can be used as a biomarker for determining air pollution. Similarly, the GST enzyme activity in the present study showed an increase in the samples collected in both summer and winter seasons from Kosuyolu and the industrial area compared to the control group.

Deniz (2010) reported that the MDA levels of the plant samples collected near a thermal power plant were high. Caregnato et al. (2010) found that ozone exposure affects different oxidative stress parameters in Phaseolus vulgaris L. species. They observed that exposure to ozon reduced the levels of non-enzymatic antioxidants but did not increase lipid peroxidation. In the present study, the MDA levels of the samples collected in summer from Kosuyolu decreased ( $p>$ $0.05)$ while these levels increased in the samples collected from the industrial area $(\mathrm{p}>0.05)$ compared to the control group. Significant increases were also observed in the samples collected in winter from both the industrial area and Kosuyolu compared to the control group ( $\mathrm{p}<0.05$ ). In areas and season where MDA levels are high, air pollution may induce free radical formation and lipid peroxidation which, when increased destroys the balance of the antioxidant system (Caregnato et al. 2010). Studies that have examined the compounding effect of meteorological conditions on air pollution found that winter worsened the air quality of both indoor air and outdoor air. Statistically significant increases were detected especially in winter due to the air pollution is more intense. The difference in the results between between the samples collected from the same areas in different seasons might be due to the the developmental phase difference of plant and the variety of human-induced air pollution activities of that season. 
The results of the present study; showed that $P$. nigra can be used as a biomonitor in determining air pollution. Biochemical biomarkers such as SOD, CAT, GP $\mathrm{X}$, GST enzymes and MDA levels in $P$. nigra needles could be useful biomarkers for biomonitoring air pollution. It was determined that seasonal changes affect the response of the biomarker. The devolopment stage also affects antioxidant parametres in different seasons. However, the differences between the results for the samples collected in the same season might be due to different air quality conditions. Statistically significant increases and decreases were detected especially in winter due to the air pollution being more intense. The different results of the biochemical biomarkers can be evaluated as an indication of possible metabolic processes responsible for the adverse effects of air pollution in plants and the biochemical response of the plants can reveal, to some extent, the environmental consequences of inadequately controlled urban air pollution in Diyarbakir. It is suggested that the obtained data could contribute to creating pollution maps for the province.

\section{Acknowledgements}

This study was supported by The Scientific Research Projects Coordination Unit of Munzur University, Project Number: YLMUB017-06.

\section{References}

Alanso R, Elvira S, Castillo FJ and Gimeno BS 2001. Interactive effects of ozone and drought stress on pigments and activities antioxidative enzymes in Pinus Halepensis. Plant Cell Environ. 24: 905-916.

Al-Alam J, Fajloun Z, Chbani A and Millet M 2017. The use of conifer needles as biomonitor candidates for the study of temporal air pollution variation in the Strasbourg region. Chemosphere 168: 1411-1421.

Andra SS, Datta R, Reddy R, Saminathan SKM and Sarkar D 2011. Antioxidant Enzymes Response in Vetiver Grass: A Greenhouse Study for Chelant Assisted Phytoremediation of Lead Contaminated Residential Soils, Clean-Soil Air Water 39: 428-436.

Caregnatoa FF, Clebschb CC, Rochaa RF, Feistauera LBH, Oliveirac PL, Divan Juniorb AD and Moreira JCF 2010. Ozone exposure differentially affects oxidative stress parameters in distinct Phaseolus vulgaris L. varieties. J. Plant Interact. 5: 111-115.

Castillo F 1987. Extracellular biochemical markers of photochemical oxidant air pollution damage to Norway spruce. Experientia, 43: 111-115.

Chiarantini L, Rimondi V, Benvenuti M, Beutel MW, Costagliola P, Gonnelli C, Lattanzi P and Paolieri M 2016. Black pine (Pinus nigra) barks as biomonitors of airborne mercury pollution. Sci. Tot. Environ. 569: $105-113$.

Chou XL 2014. Discussing issues related with detection of air pollutants. Agricul Technol. 2: 206-224.

Deniz M 2010. Effect of Thermal Power Plant Pollution on Mineral Nutrition and Antioxidative Defence Mechanism on Eucalyptus and Morus Species, PhD Thesis, Cukurova University Institute of Natural and Applied Sciences Department of Biology.

Elloumi N, Zouari M, Mezghani I, Ben Abdallah F, Woodward S and Kallel M 2017. Biochemical and physiological responses of Eriobotrya japonica to fluoride air pollution. Ecotoxicology 26: 991-1001.

Foyer CH, Noctor G 2005. Redox homeostis and antioxidant signaling: a metabolic interface between stress perception and physiological responses. Plant Cell 17: 1866-1875.

Garg N and Manchand G 2009. ROS generation in plants: boon or bane?. Plant Biosystems 143: 8-96.

Ghorbanli M, Bakand Z and Bakand S 2007. Air pollution effects on the activity of antioxidant enzymes in Nerium oleander and Robinia pseudo acacia plants in Tehran. J Environ Health Sci Eng. 4: 157-162.

Hasegawa-Kurısu K, Hama M and Hanaki K 2008. Use of GST Activity as an Evaluation Tool For Air Pollution. Environ Eng Res. 45: 211-217.

Kelly FJ and Mudway IS 2003. Protein oxidation at the air-lung interface. Amino Acids 25: 375-396. 
Krishnamurthy A and Rathinasabapathi B 2013. Oxidative stress tolerance in plants: novel interplay between auxin and reactive oxygen species signaling. Plant Signal Behav. 8: 10.

Lee EH 2000. Early Detection Mechanisms of Tolerance and Amelioration of Ozone Stress in Crop Plants. S. B. Agrowall. Environmental Pollution and Plant Responses. CRC Press LLC. s. 45-81.

Lauera N, Yeagera M, Kahna AE, Dobberfuhlb DR, Rossa C and Mittler R 2002. The effects of short term salinity exposure on the sublethal stress response of Vallisneria americana Michx. (Hydrocharitaceae). Trends Plant Sci. 7: 405-410.

Mutiu S, Atıcı Ö and Kaya Y 2009. Effect of cement dust on diversity and antioxidant enzyme activities of plants growing around a cement factory. Fresen Environ. Bull. 18: 1823 - 1827.

Noctor G, Gomez L, Vanacker H and Foyer CH 2002. Interactions between biosynthesis, compartmentation, and transport in the control of glutathione homeostasis and signalling. J. Exp. Bot. 53: 1283-1304.

Nordberg J and Arnér ESJ 2001. Reactive oxygen species, antioxidants, and the Mammalian thioredoxin system. Free Radical Bio Med. 31: 1287-1312.

Patykowski J and Kołodziejek J 2016. Changes in Antioxidant Enzyme Activities of European Mistletoe (Viscum album L. subsp. Album) Leaves as a Response to Environmental Stress Caused by Pollution of the Atmosphere by Nitrogen Dioxide. Pol. J. Environ. Stud. 25: 725-732.

Pukacka S and Pukacki PM 2000. Seasonal changes in antioxidant level of Scots pine (Pinus sylvestris L.) needles exposed to industrial pollution. II.Enzymatic scavengers activities. Acta Physiol. Plant. 22: 451456.

Radi R, Peluffo G, Alvarez MN, Naviliat M and Cayota A 2001. Unraveling peroxynitrite formation in biological systems. Free Radical Bio. Med. 30: 463-488.

Schwanz P and Polle A 2001. Growth Under Elevated $\mathrm{CO}_{2}$ Ameliorates Defenses Against Photo-Oxidative Stress in Poplar (Populus Alba X Tremula). Environ. Exp. Bot. 45: 43-53.

Schlesinger RB, Kunzli N, Hidy GM, Gotschi T and Jerrett M 2006. The health Relevance of ambient particulate matter characteristics: Coherence of toxicological and epidemiological inferences, Inhalation. Toxicology 18: 95-125.

(Manuscript received on 5 February, 2020; revised on 26 September, 2020) 